\title{
Pollution Threatens Human Fertility: It is Time to Make Our Gametes Great Again
}

\author{
Jessika Moreau, Nicolas Gatimel, Pauline Vabre, Jean Parinaud* and Roger Leandri \\ Department of Reproductive Medicine, Toulouse University Hospital, France
}

Historical examples of environmental pollution in wildlife have witnessed that mammalian reproduction is a process very highly sensitive to environmental toxins. Such example also exists in humans: it has been shown that breast-fed boys from women exposed to dioxins during the Seveso explosion have permanent reduced sperm quality. Those caricatural accidents have drawn attention on the possible links between environmental toxics and human reproduction and paved the way for studying the effects of much more insidious, chronic exposure [1-3]. The effects of toxics not only concern the exposed individuals, but also their progeny through transplacental impacts and/or epigenetic modifications with potential transgenerational inheritance, both leading to an actual problem of public health. Toxics can act on spermatogenesis as well as oogenesis, but also on embryonic and fetal development $[4,5]$.

The exposures to these toxins have different origins such as breathed air, ingested food and drinks or skin contact. They can be accidental (pollutants due to traffic or living in agricultural area) occupational (works necessitating the use of pesticides or solvents) or behavioral (smokers, alcohol drinkers). Toxics can act in 3 different ways: endocrine disruption, induction of oxidative stress and DNA modifications [6].

In women, an environmental etiology is suspected in the occurrence of premature ovarian insufficiency (POI). POI is a medical and biological diagnosis that affects young women, altering their quality of life and their fertility. It is defined as a diminished for age number of follicles which can lead to premature menopause. Since only $25 \%$ of POI have an identified etiology, environmental toxics could be responsible of this decrease in ovarian reserve. POI can be induced by toxics through 3 mechanisms. Firstly, the number of growing follicles can decrease by the induction of atresia during follicular growth via an increase of oxidative stress and apoptotic phenomena, which has been reported for bisphenol A (BPA), phthalates, pesticides and dioxins. Secondly, exposures to polycyclic aromatic hydrocarbons (PAHs), as found in tobacco smoke, or phthalates, can induce a decreased pool of primordial follicles due to a massive atresia. Moreover, genistein and BPA have been shown to induce defaults in the assembly of primordial follicles in the fetal ovary. Thirdly, phthalates and BPA can increase the recruitment of primordial follicles leading to the depletion of their stock.

In men, the decrease of sperm quality has been reported in the several countries, with a lower sperm count, motility and morphology. Environmental toxics can induce DNA fragmentation and adducts formations, mainly due to oxidative stress [7].

Moreover, endocrine disruptors may interact with the normal endocrine and/or paracrine regulation of the gonadal function, impairing gametogenesis and steroidogenic activity.

All these dysfunctions lead to a diminished pregnancy rate as reported for example in populations exposed to highly polluted air, as well as for spontaneous fertility or for in vitro fertilization. Pollution has been also implied in an increased rate of spontaneous miscarriage, diminishing even more the efficiency of the reproductive process $[8,9]$. Last, environmental toxics, mainly through endocrine function (agonist or antagonist action), can severely impair fetal development. For instance, environmental contaminants that disrupt endocrine function are highly suspected to contribute to hypospadias etiology.

Even though further studies are needed to precisely identify reproductive toxics and to decipher their mechanisms of toxicity, the available data highlight the implication of environmental toxics on reproduction [10]. While the world production of chemicals has grown very importantly over the past decades and is projected to grow at a higher rate than that of world population in the next decades, this necessitates people and authorities to be aware of the risks and to make decisions to limit exposures. According to the United States Environmental Protection Agency, in 20124.31 trillions kg of industrial chemicals were manufactured in or imported into the USA, equivalent to more than $13000 \mathrm{~kg}$ per person which may be not the best way to make our gametes great again.

\section{References}

1. Barazani Y, Katz BF, Nagler HM, Stember DS (2014) Lifestyle, environment, and male reproductive health. Urol Clin North Am 41: 55-66.

2. De Fleurian G, Perrin J, Ecochard R, Dantony E, Lanteaume A, et al. (2009) Occupational exposures obtained by questionnaire in clinical practice and their association with semen quality. J Androl 30: 566-579.

3. Den Hond E, Tournaye H, De Sutter P, Ombelet W, Baeyens W, et al. (2015) Human exposure to endocrine disrupting chemicals and fertility: A case-control study in male subfertility patients. Environ Int 84: 154-160.

4. Di Renzo GC, Conry JA, Blake J, De Francesco MS, De Nicola N, et al. (2015) International Federation of Gynecology and Obstetrics opinion on reproductive health impacts of exposure to toxic environmental chemicals. Int J Gynaecol Obstet 131: 219-225.

5. Gabrielsen JS, Tanrikut C (2016) Chronic exposures and male fertility: the impacts of environment, diet, and drug use on spermatogenesis. Andrology 4 648-661.

6. Nori F, Carbone P, Giordano F, Osborn J, Figa-Talamanca I (2006) Endocrinedisrupting chemicals and testicular cancer: a case-control study. Arch Environ Occup Health 61: 87-95.

7. Skakkebaek NE, Rajpert-De Meyts E, Buck Louis GM, Toppari J, Andersson AM, et al. (2016) Male reproductive disorders and fertility trends: influences of environment and genetic susceptibility. Physiol Rev 96: 55-97.

8. Smarr MM, Kannan K, Buck Louis GM (2016) Endocrine disrupting chemicals and endometriosis. Fertil Steril 106: 959-966.

9. Vabre P, Gatimel N, Moreau J, Gayrard V, Picard-Hagen N, et al. (2017) Environmental pollutants, a possible etiology for premature ovarian insufficiency: A narrative review of animal and human data. Environmental Health 16: 37.

*Corresponding author: Jean Parinaud, Department of Reproductive Medicine Toulouse University Hospital, France, Tel: +33567771007; Fax: +33567771015; E-mail: parinaud.j@chu-toulouse.fr

Received June 12, 2017; Accepted June 20, 2017; Published June 26, 2017

Citation: Moreau J, Gatimel N, Vabre P, Parinaud J, Leandri R (2017) Pollution Threatens Human Fertility: It is Time to Make Our Gametes Great Again. J Environ Anal Toxicol 7: 482. doi: 10.4172/2161-0525.1000482

Copyright: @ 2017 Moreau J et al., This is an open-access article distributed under the terms of the Creative Commons Attribution License, which permits unrestricted use, distribution, and reproduction in any medium, provided the original author and source are credited. 
Citation: Moreau J, Gatimel N, Vabre P, Parinaud J, Leandri R (2017) Pollution Threatens Human Fertility: It is Time to Make Our Gametes Great Again. J Environ Anal Toxicol 7: 482. doi: 10.4172/2161-0525.1000482

Page 2 of 2

10. Marrocco G, Grammatico P, Vallasciani S, Gulia C, Zangari A, et al. (2015)

Environmental, parental and gestational factors that influence the occurrence of hypospadias in male patients. J Pediatr Urol 11: 12-19. 